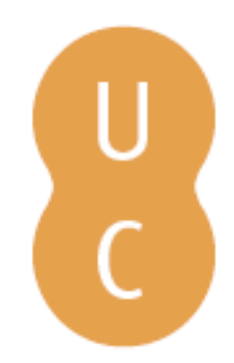

\title{
nombalina
}

\section{O Jornalismo entre a ordem, o Direito e o caos}
Autor(es):
Camponez, Carlos
Publicado por: Imprensa da Universidade de Coimbra
URL persistente:
URI:http://hdl.handle.net/10316.2/38563
DOI:
DOI:http://dx.doi.org/10.14195/978-989-26-0770-2_2

Accessed : $\quad$ 26-Apr-2023 13:56:25

A navegação consulta e descarregamento dos títulos inseridos nas Bibliotecas Digitais UC Digitalis, UC Pombalina e UC Impactum, pressupõem a aceitação plena e sem reservas dos Termos e Condições de Uso destas Bibliotecas Digitais, disponíveis em https://digitalis.uc.pt/pt-pt/termos.

Conforme exposto nos referidos Termos e Condições de Uso, o descarregamento de títulos de acesso restrito requer uma licença válida de autorização devendo o utilizador aceder ao(s) documento(s) a partir de um endereço de IP da instituição detentora da supramencionada licença.

Ao utilizador é apenas permitido o descarregamento para uso pessoal, pelo que o emprego do(s) título(s) descarregado(s) para outro fim, designadamente comercial, carece de autorização do respetivo autor ou editor da obra.

Na medida em que todas as obras da UC Digitalis se encontram protegidas pelo Código do Direito de Autor e Direitos Conexos e demais legislação aplicável, toda a cópia, parcial ou total, deste documento, nos casos em que é legalmente admitida, deverá conter ou fazer-se acompanhar por este aviso.

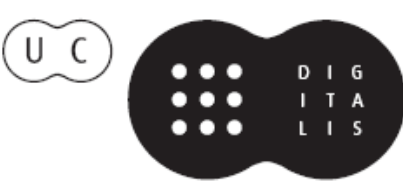



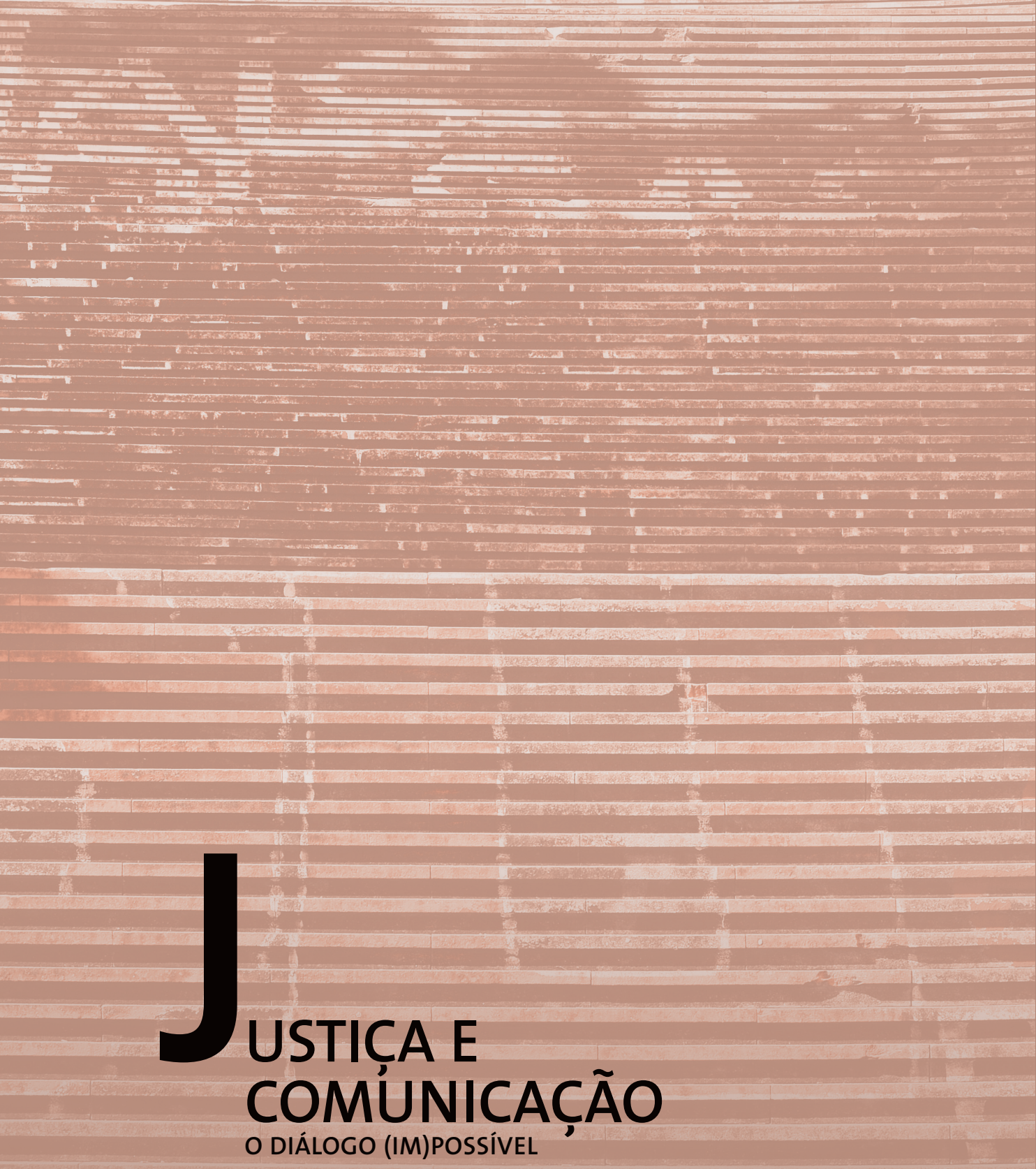

Rita Basilio Simões

Carlos Camponez

Ana Teresa Peixinho

ORGANIZAÇÃO 


\section{Carlos Camponez}

(Faculdade de Letras da Universidade de Coimbra / CEIS20)

\section{O JORNALISMO ENTREA ORDEM, O DIREITO E O CAOS}

As relações entre o direito e a deontologia desenvolvem-se no vasto campo coberto pelos fenómenos políticos e sociais de regulação e autorregulação. A nossa posição de partida neste artigo é a de que estes fenómenos são parte de um processo importante de vivência e consensualização dos valores sociais, quer no sentido de tornar efetivos os valores do direito na vida pública, quer, em sentido contrário, na perspetiva de fazer fluir os valores morais no Direito, como resultado de uma democracia que se pretende vibrante e participativa - para recuperar uma expressão de Habermas (1997: 313).

Este pressuposto parece-nos essencial quando falamos de aspetos particularmente sensíveis dos valores democráticos, como são o caso dos direitos fundamentais relacionados com a Liberdade de Expressão e a Liberdade de Imprensa. Se entendemos que o Estado deve ser o garante último dos direitos dos cidadãos, é um facto largamente aceite que a excessiva intervenção do Estado nestes domínios pode ser também um fator de perturbação dos direitos das sociedades.

É a partir deste quadro que analisaremos criticamente os processos de jurisdificação da deontologia dos jornalistas, bem como o impasse que a autorregulação socioprofissional dos jornalistas atingiu nos últimos anos. Do nosso ponto de vista, nem os poderes reguladores, nem a autonomia socioprofissional estiveram verdadeiramente ao nível das suas responsabilidades sociais. 


\section{Regulação e Autorregulação no quadro normativo contemporâneo}

Vital Moreira integra a autorregulação numa escala regulatória situada entre a autodisciplina individual e a pura regulação, da esfera exclusiva do Estado. Em rigor, a autodisciplina diz respeito às normas individuais formuladas, por exemplo, pelos indivíduos ou pelas empresas, pelo que não se deve integrar no conceito de autorregulação. Do mesmo modo, a regulação pura diz respeito aos sistemas em que o Estado monopoliza o estabelecimento, aplicação e execução das normas e que, por esse motivo, também sai fora do domínio da autorregulação ${ }^{31}$. Deste modo, entre estes dois polos, situam-se as diferentes modalidades de autorregulação: a autorregulação pura, onde a formulação e a aplicação das normas reguladoras estão nas mãos das profissões, sem qualquer interferência ou enquadramento legal; à autorregulação cooptada, em parceria com o Estado e outros organismos implicados (consumidores, por exemplo); a autorregulação negociada, que resulta de um processo de concertação e negociação com o Governo, ficando a sua aplicação dependente dos organismos profissionais; e, finalmente, a autorregulação imposta ou delegada, em que uma profissão é obrigada pelo Estado a estabelecer, aplicar e executar as normas pelas quais se deverá reger (Moreira, 1997: 79).

Diremos que a autorregulação é, ela própria uma forma de regulação, um género de regulação (Moreira, 1997: 53), nela intervindo dois elementos importantes: por um lado, a própria a ideia de regulação, isto é, "a definição de uma norma", e, por outro lado, a elaboração desta norma por parte dos seus próprios destinatários que, por consequência, «aderem a ela antecipadamente» (Van Ommeslache, 1995: 238-239).

Neste quadro de pensamento, podemos dizer que a autorregulação se insere num sistema normativo de valores morais, ou seja, valores comummente partilhados por grupos sociais que aceitam voluntariamente instituir e codificar normas e procedimentos inspirados nos valores morais, mas apli-

31 Para Vital Moreira, entram no domínio da regulação pura o Governo (Ministérios e departamentos governamentais das áreas económicas); os organismos reguladores relativamente dependentes, do tipo dos nossos institutos públicos; e os organismos reguladores independentes, do género Entidade Reguladora da Comunicação Social (Moreira, 1997: 49). 
cados às especificidades das funções e responsabilidades sociais associadas a diferentes domínios de ação, nomeadamente económicos e socioprofissionais.

Embora não possamos reduzir as formas de autorregulação à deontologia profissional, é neste sentido que Emmanuel Putman (1997: 93-94) escreve que a deontologia mais não é do que um pleonasmo de moral, na medida em que se refere ao conjunto de deveres impostos ao indivíduo no quadro do exercício da sua profissão. Do mesmo modo, Philippe Stoffel-Munck salienta que moral e deontologia mantêm uma relação muito próxima, ao ponto de a deontologia poder ser considerada uma expressão da moral, enquanto conjunto de regras de consciência aplicáveis no âmbito de algumas profissões (Stoffel-Munck, 1997: 63). Neste contexto, falamos, então, de uma consciência moral coletiva, partilhada no âmbito de uma profissão (Aznar, 2005: 48).

\section{A autorregulação no quadro normativo contemporâneo}

Falar, portanto, de autorregulação é refletir sobre um campo normativo de confluência das dimensões filosófica e jurídica. Seguindo o pensamento de Victoria Camps a este propósito, no plano filosófico, a autorregulação coloca-se no plano ético e evoca a questão da autonomia dos sujeitos, entendida esta, no sentido kantiano do termo, como a capacidade de os indivíduos se autorregerem de acordo com normas ditadas pela sua consciência. A autonomia representa, assim, a condição da possibilidade do comportamento responsável e amadurecido (Camps, 2004: 234) ${ }^{32}$. No plano do direito, a autorregulação é objeto do tratamento político e jurídico, estabelecendo as condições e os objetivos do seu exercício. Por isso, conclui Camps, a autorregulação é «a melhor maneira de combinar a necessidade de normas com o exercício da liberdade» (Camps, 2004: 235).

32 Para Victoria Camps, a "(...) autorregulação e autonomia são um mesmo conceito. A autonomia consiste, literalmente, na capacidade do indivíduo em eleger as suas próprias normas. Ser autónomo não equivale, simplesmente, a ser independente ou anárquico, mas em ser consciente de que existe ou deve haver regras de conduta que o sujeito autónomo aceita e reconhece livremente» (Camps, 2004; 235). 
Deste modo, a confluência dos domínios filosófico e jurídico atribui à deontologia o papel de medium entre a moral e o direito, sendo, dessa forma, uma das expressões da «irrupção dos valores no direito" e constitui um exemplo das possibilidades de existência de um "encavalgamento" entre direito e moral» (Bergel, 1997: 10. Pode-se, deste modo, entender a progressiva sedimentação e integração dos valores profissionais na ordem jurídica. Mas as relações entre o direito e a deontologia não se fazem necessariamente no sentido de uma sedimentação dos valores profissionais em leis. Quer a filosofia dos valores quer a sociologia notam que o denominado processo de deontologização a que assistimos nas sociedades contemporâneas afeta, de uma forma aparentemente contraditória, profissões já previamente enquadradas e reconhecidas legalmente, mas que buscam na adoção dos códigos deontológicos esse supplément d'âme (Stoffel-Munck, 1997: 69) que, aparentemente, não encontram na lei. Para além disso, a ideia de uma confluência entre estes domínios normativos, simultaneamente distintos e complementares, não se faz sem conflitos como o demonstram, por exemplo, no caso português, as questões referentes aos casos do sigilo profissional dos jornalistas e as resistências manifestadas pela Ordem dos Médicos à alteração do artigo $47 .^{\circ}$ do Código Deontológico, que considerava a prática de aborto como uma "falha grave", contrariando a lei e a opinião da maioria dos portugueses expressa em referendo ${ }^{33}$. Com efeito, a deontologia extravasa o domínio do direito e, nesse sentido, completa-o, através de uma perceção diferente dos deveres, que não obedecem apenas a uma lógica de respeito da lei. É neste contexto que Daniel Cornu afirma que «fazer

33 No jornalismo, esta situação ficou bem patente com o caso Manso Preto, em que o jornalista foi julgado por se recusar a revelar uma fonte de informação. O exemplo mais recente deste conflito entre norma jurídica e dever deontológico ficou patente na decisão do Ministério da Saúde, de novembro de 2007, de fazer uma queixa ao Ministério Público face à recusa da Ordem dos Médicos em alterar o ponto 47. ${ }^{\circ}$ do Código Deontológico, que considera a prática de aborto como uma "falha grave», contrariando a lei e a opinião da maioria dos portugueses expressa em referendo. No novo Código Deontológico, adotado em 27 de setembro de 2008, desaparece a referência direta a práticas abortivas e adota-se uma formulação mais vaga. Refere-se no art. ${ }^{\circ} 55 .^{\circ}$ que o médico "deve guardar respeito pela vida humana desde o momento do seu início», acrescentando-se de seguida (art. ${ }^{\circ} 56 .{ }^{\circ}$ ) que isso não é impeditivo que se adotem terapêuticas destinadas a preservar a vida da grávida. 
"bom jornalismo", no sentido ético, não se fica pelo simples respeito das leis» (Cornu, 1994:54) ${ }^{34}$.

\section{A autorregulação e nova Governança}

Longe de poder ser vista apenas como o resquício de formas arcaicas corporativistas, a autorregulação profissional é, nas palavras de Vital Moreira, «a resposta comum a problemas comuns dos Estados administrativos e reguladores dos nossos dias»35. A sua importância foi consagrada no plano europeu, nomeadamente, no Tratado de Maastricht, em 1992, no Livro Branco Sobre a Governança Europeia, em 2001, e, no acordo interinstitucional "Melhor Legislar", em dezembro de 2003.

Referindo-se ao caso alemão, Leo Kisseler e Francisco Heidemann consideram que esta noção de governança ou nova governação começou por se apresentar como uma resposta à administração pública gerencial (new public management), que corresponde ao modelo ideológico do Estado em que as administrações se tornaram mais empresariais, menos onerosas e, em geral, mais eficientes (Kisseler e Heidemann, 2006) ${ }^{36}$. Mas as políticas de nova governação procuram representar algo mais do que uma correção destinada a minorar os problemas suscitados pela reforma administrativa do Estado. Com efeito, a nova governação passou a denominar o conjunto de medidas visando ajustar a administração pública aos desafios da governabilidade das sociedades complexas e da economia globalizada. Entre outros objectivos, pretende-se superar a crise orçamental das organizações públicas, dar conta dos novos valores emergentes nas sociedades modernas e responder às novas expectativas dos cidadãos por um Estado eficiente, a partir das novas possibilidades de participação e envolvimento dos cidadãos

${ }^{34}$ D. CORNU, L'Éthique de L'Information, op. cit., p. 55.

35 V. MOREIRA, Auto-Regulação Profissional e Administração Pública, op. cit, p. 389.

${ }^{36}$ Porém, segundo os autores, na prática, este modelo ficou marcado por medidas de redução de postos de trabalho na administração pública, em detrimento de efetivas melhorias no que diz respeito ao serviço prestado aos cidadãos. A procura de novas formas de governação surge, neste contexto, como uma resposta às insuficiências da administração pública gerencial. 
(Moreira, 1997: 481). Neste sentido, estamos perante um conceito destinado a descrever também todo o espectro regulatório resultante de formas de cooperação entre a sociedade civil organizada e o Estado, onde as profissões altamente qualificadas se apresentam como as guardiãs de "uma certa forma de subpolítica normalizada" (Moreira, 1997: 47). Como refere Carlos Jalali, estamos já a falar de uma "terceira vaga da democracia», em que o debate deixa de ser sobre os "méritos da democracia liberal» para se centrar na questão da "qualidade da democracia", que envolve não só as estruturas sociais, mas também os cidadãos no exercício dos seus direitos ${ }^{37}$.

\section{Regulação e autorregulação do jornalismo}

É neste quadro que pretendemos analisar a autorregulação do jornalismo português, bem como as evoluções verificadas no campo de jurisdificação dos valores sócio profissionais, desde os anos 90. Com efeito, 1990 marca, a nosso ver, o início de importantes alterações no edifício regulatório da comunicação, colocando a nu as debilidades da autorregulação dos jornalistas e abrindo um processo profundo de crise que culminará com o que denominaremos pela captura da autorregulação profissional por parte do Estado.

A crise a que nos referimos tem a ver com quatro fatores fundamentais:

1. A extinção do Conselho de Imprensa;

2. A forma mal assumida do modelo de organização sindical inspirada no modelo corporativista do Estado Novo;

3. A erosão de representatividade do Sindicato dos Jornalistas;

4. A jurisdificação da deontologia do jornalismo e o reforço do quadro regulador dos media.

37 Segundo o autor, este alto nível de exigência democrática contrasta com a situação portuguesa onde se registam índices reduzidos em termos de participação associada e de automobilização política. Este padrão de comportamento encaixa com os estados de desafeição e de descontentamento que levam muitos cidadãos a optarem não só pela "saída" em termos da sua participação política, como pela "negligência" , assumindo atitudes de passividade e inação (Jalali, 2005: 36). 


\subsection{A extinção do Conselho de Imprensa}

A extinção do Conselho de Imprensa, em 1990, e a sua substituição pela Alta Autoridade para a Comunicação Social representou um duro golpe no sistema de autorregulação dos jornalistas vigente, desde os primeiros anos da Revolução de Abril. Esta substituição teve por objetivo criar as condições para regular a exploração das ondas de rádio e de televisão por operadores privados. Porém, o Conselho de Imprensa era também um órgão de corregulação ética e deontológica do jornalismo, que reunia representantes da Assembleia da República, dos jornalistas, dos media e do público. No entanto, o Estado descorou essa dimensão com o argumento de que «a defesa das questões éticas cai no âmbito das atribuições da sociedade civil e não nas atribuições do Estado" (Figueiredo e Costa, 1990; Antunes, 1990: 9).

A extinção do Conselho de Imprensa acabou por fazer com que os jornalistas se sentissem órfãos da autorregulação. Na realidade, esta encontrava-se fortemente respaldada no Conselho de Imprensa, o que permitiu que o Conselho Deontológico do Sindicato dos Jornalistas praticamente se limitasse a exercer uma autorregulação intraprofissional, na medida em que a maioria das questões suscitadas pelo público passavam privilegiadamente pelas discussões com sede no organismo de corregulação. Com efeito, foi apenas após a extinção do Conselho de Imprensa que o Conselho Deontológico do Sindicato dos Jornalistas acabaria por aceitar receber, anos mais tarde, de uma forma sistemática, as queixas apresentadas pelo público.

Assim, é legítimo dizer-se que, de 1974 até 1990, a autorregulação dos jornalistas - em estrito senso - é fundamentalmente autocentrada: de jornalistas, por jornalistas e para jornalistas.

Não é, portanto, estranho que depois dos protestos contra a extinção do Conselho de Imprensa, os jornalistas tenham pugnado para a criação de uma estrutura alternativa, o então denominado "Conselho de Imprensa Privado». Porém, sem sucesso, em grande medida porque os empresários da comunicação social, considerados os parceiros naturais desta estrutura, não aceitaram. 


\subsection{Entre Sindicato Público e Ordem}

Data ainda desta altura um outro acontecimento que nos parece decisivo para a compreensão da atual situação da autorregulação dos jornalistas portugueses: a proposta de criação de uma Ordem, por parte da Associação Portuguesa de Jornalistas.

Entre outros aspetos, os defensores da Ordem consideram que o Sindicato não é a instância adequada para a discussão dos temas do foro deontológico (Albino, 2003: 17). O Código Deontológico era também considerado ineficiente, correspondendo apenas a uma carta de ética que se limita a enunciar uns poucos princípios vagos, norteadores da deontologia. Para além disso, entre os defensores da Ordem estão os que consideram que as atuais condições de exercício da profissão colocaram o jornalista numa situação particularmente permeável à degradação dos padrões éticos e profissionais, exigindo o reforço da autorregulação, por via institucional, sem a "promiscuidade entre funções sindicais com as funções deontológicas» (Silva, 2006).

O projeto foi liminarmente recusado num referendo levado a cabo pelo Sindicato dos Jornalistas junto dos profissionais. Dessa discussão ressalta a recusa de os jornalistas se organizarem numa Ordem profissional, uma estrutura conotada com uma tradição corporativa, que fazia recordar o Estado Novo. Esta formulação superficial do problema fez com que os jornalistas, em 1975, se tivessem dado por satisfeitos com a alteração do nome do Sindicato Nacional dos Jornalistas para, simplesmente, Sindicato dos Jornalistas, crendo que, com a eliminação da designação "Nacional", se limpava toda a sua dimensão corporativa, vista essencialmente de forma negativa. Assim, nunca foi verdadeiramente questionado o que representava para o Sindicato dos Jornalistas deter, simultaneamente, no seu seio, funções de regulação e representação da profissão, bem como de defesa das relações laborais. Deste modo, ficou também por fazer uma análise profunda sobre as formas de organização da profissão, e sobre a verdadeira natureza da estrutura do Sindicato, antes e depois do 25 de Abril.

Ironicamente, ao iludir esta questão, dir-se-ia que o debate entre o Sindicato dos Jornalistas e os defensores da Ordem profissional, mais 
do que uma discussão em torno de um modelo representativo, resumiu-se a uma luta de poder e de controlo sobre a profissão: por um lado, tínhamos os defensores do Sindicato que rejeitavam o projeto corporativo da Ordem sem ter uma consciência exata que ele estruturava, em grande medida, a própria organização sindical; por outro lado, tínhamos os defensores da Ordem que criticavam o Sindicato por este usurpar o espaço político-representativo de uma futura Ordem.

\subsection{A Comissão da Carteira Profissional de Jornalista}

A discussão em torno da Ordem dos jornalistas teve outras repercussões plenas de consequências para a autorregulação socioprofissional. Com efeito, a Associação Portuguesa de Jornalistas suscitou a inconstitucionalidade da Lei de Imprensa, do Estatuto dos Jornalistas e do Regulamento da Carteira Profissional, nomeadamente nos artigos em que se atribui à organização sindical poderes sobre o universo dos jornalistas. Do mesmo modo, contestam-se também os artigos dos estatutos do Sindicato que atribuem ao Conselho Deontológico a responsabilidade pela emissão e revalidação anual da carteira profissional, pela análise de todos os casos de infração ao Código Deontológico, ao Estatuto do Jornalistas e ao Regulamento da Carteira, bem como a aplicação das respetivas sanções ${ }^{38}$.

Esta história terminou, em 1993, com a declaração de inconstitucionalidade de atribuição ao Sindicato de Jornalistas das competências em matéria de atribuição, renovação e cassação dos títulos profissionais e com a criação, em 1996, da Comissão da Carteira Profissional de Jornalista.

38 Em carta enviada ao Provedor de Justiça, Carlos Albino, presidente da Associação, pedia ainda que se considerasse a emissão de "uma recomendação legislativa ou sugestão» no sentido de que a Assembleia da República ou o Governo legislassem sobre a criação de uma associação pública dos jornalistas com competências para se ocupar especificamente da regulamentação do exercício da profissão, designadamente nos seus aspetos deontológicos e disciplinares. Considerava ainda o presidente da Associação Portuguesa de Jornalistas que, uma vez regulamentados estes aspetos, os poderes do Estado nesta matéria deveriam ser devolvidos a uma pessoa autónoma, a quem seria atribuída a administração das respetivas competências [Segundo exposição de 18/02/92, enviada por Carlos Albino, na qualidade de presidente da Associação Portuguesa de Jornalistas, a Meneres Pimentel, Provedor de Justiça]. 
Este aspeto é relevante, a nosso ver, por duas razões. Em primeiro lugar porque, pela primeira vez na sua história, o Sindicato dos Jornalistas perde o controlo efetivo sobre o conjunto dos profissionais.

Em segundo lugar, porque a criação da Comissão da Carteira Profissional de Jornalista acabará por se transformar, no futuro, num dos polos em que se organizará todo o processo de jurisdificação da deontologia e da autorregulação profissional. Com efeito, a Comissão da Carteira Profissional de Jornalista começou, em 1994, por ser apenas uma entidade que tinha por objetivo a regulação do acesso à profissão. Porém, ela evoluiu para um modelo mais institucionalizado, marcado, por um lado, pela restrição do seu carácter intraprofissional, com a inclusão de representantes dos proprietários dos media, em $1997^{39}$, e pelo alargamento das suas competências à análise e sanção de questões do foro deontológico, em $2008^{40}$.

\subsection{A Entidade Reguladora da Comunicação Social e os poderes sobre a deontologia}

Outro aspeto dessa jurisdificação não deixa de se verificar com a criação da Entidade Reguladora da Comunicação Social (Lei n. ${ }^{\circ}$ 53/2005 de 8 de novembro), que assume responsabilidades para se pronunciar acerca de questões deontológicas, através das competências que lhe foram outorgadas em matéria de vigilância do rigor informativo dos órgãos de comunicação social e de proteção dos direitos de personalidade dos cidadãos ${ }^{41}$.

Curiosamente, este processo de jurisdificação da deontologia do jornalismo foi objeto de forte crítica da Entidade Reguladora da Comunicação Social, aquando da discussão pública da Proposta de Lei que revia o Estatuto do Jornalista. Entre outros aspetos, criticava-se a forma como se amalgamavam os universos do direito e da ética do jornalismo; a introdução no

39 Através do Decreto-Lei 305/97, de 11 de novembro) que lhe atribui o estatuto de entidade pública independente.

40 De acordo com o Decreto-Lei n. ${ }^{\circ} 70 / 2008$ de 15 de abril.

41 Conforme as alíneas a) e f), do art. $7 .^{\circ}$, referente aos objetivos da regulação. 
sistema legislativo da indeterminação própria de alguns conceitos de natureza deontológica, como por exemplo, "sensacionalismo", e "abuso da boa fé do público»; a reescrita da deontologia profissional no seu processo de vazamento na lei; e o reforço das responsabilidades do jornalista, sem a correspondente exigência dos empresários de comunicação social.

Finalmente, foi ainda questionada a possibilidade de o atual modelo criar conflitos positivos entre a área de atuação da Entidade Reguladora da Comunicação Social e as competências da Comissão de Carteira Profissional de Jornalista. Ainda que se pretenda que as competências da Entidade Reguladora incidam sobre os órgãos de comunicação social e as da Comissão da Carteira sobre os jornalistas, o parecer sublinha que existe o risco de sobreposição de áreas e, em consequência, riscos de contradição de apreciações. A este propósito, refere-se ainda que «a avaliação do rigor informativo está na base de qualquer juízo de valor que se possa fazer sobre condutas jornalísticas, não sendo aceitável que entidades diferentes possam dar origem a pronunciamentos contraditórios a respeito do mesmo assunto". Neste sentido, o documento sugere que se deveria devolver aos meios profissional e empresarial, pela via da autorregulação, aquilo que é o cerne da deontologia, enquanto expressão de uma consciência meta-jurídica, proveniente de dentro para fora do sistema mediático e em sentido contrário da proposta subjacente à iniciativa do governo (Conselho Regulador, 2006: 21).

\subsection{A erosão da representatividade do Sindicato dos Jornalistas}

Remando contra a corrente, em matéria de autorregulação, nomeadamente no que se refere às questões de natureza deontológica, o Conselho Deontológico do Sindicato dos Jornalistas, assume, a partir de 1996, uma das fases mais intervenientes, quer ao nível socioprofissional quer ao nível público. Porém, a sua representatividade começa a baixar significativamente, enquanto o Estado se prepara para atribuir muitas das sua tradicionais funções a organismos exteriores à autorregulação. O 2. ${ }^{\circ}$ Congresso de Jornalistas, em 1982, o próprio Sindicato 
de Jornalistas, em 1990 e 1993, e o 3. ${ }^{\circ}$ Congresso de Jornalistas, em 1997, preconizaram a criação de um organismo de ética e deontologia profissional independente e alargado a toda a classe dos jornalistas ${ }^{42}$. Razões de inépcia, umas vezes, cálculo político, outras vezes, e, ainda, as dificuldades estatutárias de manter um conselho deontológico como um órgão do Sindicato dos Jornalistas, mas ao mesmo tempo aberto a todos, contribuíram para que essa vontade expressa nas reuniões magnas dos jornalistas portugueses nunca se viesse a concretizar.

Enquanto isto, hoje, quando o Conselho Deontológico se pronuncia contra o comportamento profissional de um sócio, continua a confrontar-se com a "retaliação» deste último, através da sua desvinculação do Sindicato dos Jornalistas (Mesquita, s.d.: 207; Mascarenhas, s.d.: 210), pondo em causa a legitimidade moral daquele órgão, e dando razão aos que consideram que, efetivamente, os jornalistas não se querem autorregular ou só o fazem episodicamente, quando, de alguma forma, se sentem ameaçados nos seus direitos (Serrano, 2007).

Sobre as intenções que presidiram a esta jurisdificação e captura pelo Estado da autorregulação do jornalismo, são esclarecedoras as palavras do próprio ministro dos Assuntos Parlamentares, Augusto Santos Silva, que tutelou a pasta da Comunicação Social, até outubro de 2009, quando defendeu a necessidade de um reforço dos poderes de regulação do Estado, como forma de obrigar os órgãos de informação a interpelarem-se a si mesmos e a serem interpelados a partir do conjunto dos cidadãos. Para aquele governante, tratava-se de combater o «libertarismo ideológico

42 Várias razões explicam este facto: em primeiro lugar, porque os jornalistas assentaram a sua autorregulação num modelo mal assumido, algures entre ordem e sindicato público, vendo no conceito de "corporação" mais uma acusação do que uma vocação, não retirando, por isso, daí todas as suas consequências. Esse modelo entra verdadeiramente em rutura a partir do momento em que é declarada a inconstitucionalidade dos poderes delegados pelo Estado ao Sindicato dos Jornalistas - e exercidos pelo Conselho Deontológico - na atribuição e revalidação da carteira profissional. Em segundo lugar, devido à impossibilidade estatutária de transformar o Conselho Deontológico do Sindicato dos Jornalistas num órgão associativo, mas alargado a todos os profissionais. Em terceiro lugar, devido à incapacidade de o Sindicato de Jornalistas assegurar, por si só, uma estrutura que fosse capaz de substituir algumas das funções atribuídas ao extinto Conselho de Imprensa. Em quarto lugar, porque não existiram outros parceiros interessados em erguer um sistema de autorregulação alternativo ao modelo de corregulação partilhado entre o poder político representado na Assembleia da República, os representantes do público, empresários da comunicação social e jornalistas. 
e o orgulho profissional» dos jornalistas, bem como o liberalismo económico dos empresários, através dos deveres do Estado e dos instrumentos de regulação ao seu dispor, com vista a articular os direitos de liberdade de expressão e de imprensa com os restantes direitos, liberdade e garantias pessoais. Deste modo, o endurecimento dos poderes reguladores surge como uma resposta à evolução patente, sobretudo, na informação da televisão generalista e da imprensa tabloide que, sistematicamente, segundo Santos Silva, vêm "sacrificando e sacrificando tantos direitos de personalidade», nomeadamente os referentes à imagem, à palavra, à privacidade, entre outros (Silva, 2007).

\section{Conclusão}

Confrontamo-nos hoje com uma situação paradoxal. Se, em 1990, entre as razões apontadas para a extinção do Conselho de Imprensa, o argumento utilizado foi o de que "a defesa das questões éticas cai no âmbito das atribuições da sociedade civil e não nas atribuições do Estado", em 2008, é em nome da mesma sociedade civil e das mesmas questões éticas que o Estado decide intervir, criando novos organismos, reforçando os poderes de outros e avançando no campo da autorregulação como nunca antes o tinha feito. Fê-lo em resposta a um modelo de (auto) regulação que os jornalistas nunca conseguiram ou souberam pôr de pé, mas que o Estado também contribuiu para desmantelar; fê-lo, ainda, num contexto de regulação dos meios de comunicação, criando uma Entidade Reguladora da Comunicação Social e sobrepondo competências entre entidades de regulação, de corregulação e de autorregulação; fê-lo, finalmente, juridificando a deontologia do jornalismo e impondo um novo regime disciplinar e sancionatório transformando a autorregulação do jornalismo numa "autorregulação capturada».

Desde a Revolução de Abril que poderíamos dizer que as questões éticas e deontológicas do jornalismo viveram num contexto insustentável de uma autorregulação publicamente incipiente. A forma mais acabada da sua realização foi no âmbito de um sindicato "descorporatizado" 
que, no entanto, num quadro de liberdade associativa, manteve muitas das suas características dos "sindicatos" públicos", integrando, funções de regulação, representação e de defesa dos interesses laborais. Esta situação é tanto mais estranha quanto, quando a questão da Ordem dos jornalistas se colocou, imediatamente emergiram os fantasmas do Estado Novo. A questão não seria tão grave se o Sindicato de Jornalistas mantivesse, hoje, os níveis de representatividade da classe que, nessa altura, rondavam os 90 por cento dos profissionais com carteira profissional. Mas a erosão constante dessa representatividade fez com que as iniciativas de redinamizar a autorregulação através do Conselho Deontológico se revelassem infrutíferas e se questionasse, inclusivamente, a legitimidade daquele órgão em se pronunciar sobre o conjunto dos profissionais.

Em alternativa, como vimos, assistimos à multiplicação de meios de regulação do jornalismo por parte do Estado. Hoje, as questões da autorregulação da profissão estão distribuídas pela Entidade Reguladora da Comunicação Social, a Comissão da Carteira Profissional dos Jornalistas e o Sindicato dos Jornalistas, três organismos que se pronunciam sobre questões de ética e deontologia profissional. Esta situação não só põe em causa o princípio inscrito na Federação Internacional dos Jornalistas segundo o qual, os jornalistas, em matéria profissional, apenas aceitarão a jurisdição dos seus pares, como demonstra bem o caos em que o sistema se arrisca a transformar, com o Conselho Deontológico, a Comissão da Carteira Profissional de Jornalistas e a Entidade Reguladora da Comunicação Social a pronunciarem-se sobre os mesmos casos e as mesmas queixas. 


\section{B I B L I O G R A F I A}

AFONSO, O. (2005). "Dever de reserva - O seu papel na jurisdição". In: AA VV, Balanço da reforma da acção executiva. Segredo de justiça e dever de reserva (Conselho Superior da Magistratura, II Encontro Anual - 2004). Coimbra: Coimbra Editora, pp. 147-154.

ALBINO, C. (2003). «Sim, a Ordem dos Jornalistas». In: Diário de Notícias, 2 de novembro.

AMSELEK, P. (1964). Méthode phénoménologique et théorie du droit. Paris: L.G.D. J.

ANTUNES, F. (1994). "Alta Autoridade está queimada». In: Jornal de Notícias, 14 de março.

AZNAR, H. (2005). Comunicação Responsável - A auto-regulação dos media. Porto: Porto Editora.

BARREIROS, J. A. (2005). "O dever de reserva nas profissões jurídicas». In: AA VV, Balanço da reforma da acção executiva. Segredo de justiça e dever de reserva (Conselho Superior da Magistratura, II Encontro Anual - 2004). Coimbra: Coimbra Editora, pp. 163-170.

BARTHES, R. (1984). O rumor da língua. Lisboa: Ed. 70, (trad. portuguesa).

BECKETT, K. e WESTERN, B. (2001). "Governing social marginality: welfare, incarceration and the transformation of state policy". In: Punishment and Society, 1, pp. 43-59.

BENHABIB, S. (2009). "Rumo a um modelo deliberativo de legitimidade democrática». In: MARQUeS, A. (ed.), A Deliberação Pública e suas Dimensões Sociais, Políticas e Comunicativas. Belo Horizonte: Autêntica Editora.

BERGEL, J-L. (1997). "Du concept de déontologie à sa consécration juridique». In: BERGEL, J-L, (org.), Droit et Déontologies Professionnelles. Aix-en-Provence: Librairie de l'Université.

BHATIA, V. K. (1993). Analysing Genre: Language Use in the Professional Setting. London: Longman.

BHATIA, V. K. (1994). Cognitive structuring in legislative provisions. In: GIBBONS, J. (ed.). Language and the Law. London: Longman.

BHATIA, V. K. (2010). Legal writing: specificity. Specification in legislative writing: accessibility, transparency, power and control. In: Coulthard, M. e Johnson, A. (eds.) 2010. The Routledge Handbook of Forensic Linguistics. London: Routledge.

BIRESSI, A. e NUNN, H. (2003). "Video justice: crimes of violence in social/media space». In: Space \& Culture, 6 (3): pp. 276-291.

BOBBIO, N. (1982). A teoria das formas de governo. Brasília: UnB.

BOBBIO, N. (2000). O futuro da democracia. São Paulo: Paz e Terra.

BOHMAN, J. (2000). "The division of Labor in Democratic Discourse: Media, Experts, and Deliberative democracy». In: Chambers, S. and Costain, A. N. (org). Deliberation, Democracy and the Media. Maryland: Rowman \& Littlefield Publishers. 
BOTTOMS, A. E. (1995). «The philosophy and politics of punishment and sentencing». In: Clakson, C. and Morgan, R. (eds.). The Politics of Sentencing Reform. Oxford: Clarendon Press.

BRES, J. (2005). "Savoir de quoi on parle: dialogue, dialogal, dialogique; dialogisme, polyphonie...» In: Bres, J.; Haillet, P.P.; Mellet, S.; Nølke, H. e Rosier, L. (dirs.). Dialogisme et polyphonie. Approches linguistiques. Bruxelles: De Boeck.

BRKIC, J. e ANDERSON, N. (1988). Drafting and Interpreting Legal Documents. In: Kevelson, R. (ed.). Law and Semiotics. Vol. 2. New York: Plenum Press.

CALHOUN, C. (1996). "Introduction: Habermas and the public sphere». In: Calhoun, C. (ed.) Habermas and the Public Sphere. 4. ${ }^{\mathrm{a}}$ ed., Cambridge: MIT Press, pp. 1- 48.

CAMPS, V. (2004). «Instituiciones, agencias y mecanismos de supervisión mediática». In: CONILL SANCHO, J.; GONZÁLEZ, V. (coords.). Ética de los Medios - Una apuesta por la ciudadanía audiovisual. Barcelona: Editorial Gedisa.

CANIVET, G. e JOLY-HURARD, J. (2004). La déontologie des magistrats. Paris: Dalloz.

CANotilho, G. e MOReira, V. (2007). Constituição da República Portuguesa Anotada, vol. I. Coimbra: Coimbra Editora.

CARAPINHA, M. C. (2006). Contributos para a análise da linguagem jurídica e da interacção verbal em sala de audiências. Dissertação de Doutoramento (não publ.). Coimbra: Faculdade de Letras.

CARMO, R. do (2005). "O dever de reserva - O dever de informar: algumas achas para o debate». In: AA VV, Balanço da reforma da acção executiva. Segredo de justiça e dever de reserva (Conselho Superior da Magistratura, II Encontro Anual -2004). Coimbra: Coimbra Editora, pp. 155-162.

CARPINI, M. D. e WILliAMS, B. A. (2001). «Let Us Infotain You: Politics in the New Media Environment». In: Bennet, W. L.; Entman, R. M. (eds). Mediated politics: communication in the future of democracy. Cambridge: Cambridge University Press, pp. 160-181.

CASTELLS, M. (1999). O poder da identidade (A era da informação: economia, sociedade e cultura; v.2). São Paulo: Paz e Terra.

CHERMAK, S. M. (1995). Victims in the News. Crime and the American News Media. Boulder, San Francisco, Oxford: Westview.

CHIBNALL, S. (1977). Law-and-Order News: An Analysis of Crime Reporting in the British Press. London: Tavistock Publications.

CHRISTIE, G. C. (1964). "Vagueness and Legal Language». In: Minnesota Law Review, 48.

COHEN, J. (1997). Deliberative Democracy. Cambridge: MIT Press.

COHEN, J. (2009). "Deliberação e legitimidade democrática». In: Marques, A. (ed.). A Deliberação Pública e suas Dimensões Sociais, Políticas e Comunicativas. Belo Horizonte: Autêntica Editora.

COHEN, S. (2002). Folk Devils and Moral Panics. The Creation of the Mods and Rockers, 3. ${ }^{\mathrm{a}}$ ed. London, New York: Routledge.

COHEN, S. e YOUNG, J. (1973). The Manufature of News: Deviance, Social Problems and the Mass Media. London: Constable.

CONSELHO REGULADOR (2006). Parecer Relativo ao Anteprojecto da Proposta de Lei que Altera o Estatuto dos Jornalista - Parecer 2/2006.

CORNU, G. (2000). Linguistique Juridique. $2^{\text {a }}$. Ed. Paris: Montchrestien.

CORNU, D. (1994). Journalisme et Vérité. Genebra: Labor et Fides.

CORREIA, J. C. (2005). Sociedade e Comunicação: Estudos sobre Jornalismo e Identidades. Covilhã: UBI. 
COULTHARD, M. e JOHNSON, A. (2007). An Introduction to Forensic Linguistics. Language in Evidence. London: Routledge.

COUlthARD, M. e JOHNSON, A. (eds.) (2010). The Routledge Handbook of Forensic Linguistics. London: Routledge.

CURTIS, P. (2001). Jack the Ripper and the London press. New Haven: Yale University Press.

DOUGLAS, M. (1986). How Institutions Think. New York: Syracuse University Press.

DRYZEK, J. (2004). "Legitimacy and economy in deliberative democracy» In: Farrely, C. Contemporary Political Theory: a Reader. London: Sage.

DRYZEK, J. (2000). Deliberative Democracy and Beyond: Liberals, Critics, Contestations. Oxford: Oxford University Press.

DUBOUCHET, P. (1990). Sémiotique Juridique. Paris: PUF.

DUCROT, O. (1982). La notion de sujet parlant. In: Cahier du Groupe de Recherches sur la Philosophie et le langage, 2. Grenoble: Université de Grenoble.

DUCROT, O. (1984). Le Dire et le dit. Paris: Minuit.

DURKHeIM, É. (1977). A Divisão do Trabalho Social, Vol. 1, trad. de M. I. Freitas. Lisboa: Editorial Presença.

EAGLETON, T. (2000). Ideology: an Introduction. 7. ${ }^{\mathrm{a}}$ ed. London: Verso.

ELSTER, J. (1986). "The Market and the Forum: Three Varieties of Political Theory". In: Elster, J.; Hylland, A. (eds). Foundations of Social Choice Theory, Cambridge: Cambridge University Press, pp. 104-132.

ELSTER, J. (1998). Deliberative Democracy. Cambridge: Cambridge University Press.

ERICSON, R., BARANEK, P. e CHAN, J. (1989). Negotiating Control: A Study of News Sources. Toronto: University of Toronto Press.

ESSER, F. (1999). "Tabloidization of news. A comparative analysis of Anglo-American and German Press Journalism». In: European Journal of Communication, pp. 291-324.

FARIA, J. E. (1986). "A Reforma do Ensino Jurídico». In: Revista Crítica de Ciências Sociais, 21.

FERNANDES, P. C. (2008). "Justiça e media: legitimação pela comunicação». In: Revista do CEJ $\left(n .^{\circ} 10\right)$, pp. 311-346.

FIGUEIREDO, C. e COSTA, R. (1990). "Alta Autoridade da discórdia». In: Expresso - Suplemento A4, 27 de janeiro.

FONSECA, J. (1994). "O lugar da Pragmática na Teoria e na Análise Linguísticas». In: Pragmática Linguística. Introdução, Teoria e Descrição do Português. Porto: Colecção Linguística/Porto Editora, n. ${ }^{\circ} 5$.

FOUCAUlT, M. (1991). Vigiar e Punir: Nascimento da Prisão. 9. ${ }^{a}$ ed., trad. de L. M. P. Vassallo. Petrópolis: Vozes.

FOX, R. L. e SICKEL, R. V. (2001). Tabloid Justice: Criminal Justice in an Age of Media Frenzy. London: Lynne Rienner Publishers Boulder.

FRANKLIN, B. (1997). Newszak \& News Media. London: Hodder Arnold.

FRASER, N. (1996). "Rethinking the public sphere: a contribution to the critique of actually existing democracy» In: Calhoun, C (ed.) Habermas and the Public Sphere. 4. ${ }^{a}$ ed., Cambridge: MIT Press, pp. 109-142.

FRIEDMAN, L. M. (1964-1965). Law and its Language. In: George Washington Law Review, p. 33.

FUENTES GONZÁLEZ, D. (1997). Algunas aportaciones de la sociolingüística al campo del derecho. In: Delgado León, F.; Calero Vaquera, M. L. e Osuna García, F. (eds.), (1998). 
Actas del II Simposio de Historiografía Lingüística. Córdoba: Servicio de Publicaciones de la Universidad de Córdoba.

GALVÃO TELLES, I. (2000). Introdução ao Estudo do Direito. Vol. II. 10 ${ }^{\mathrm{a}}$ ed. Coimbra: Coimbra Editora.

GARAPON, A. (1998). O guardador de promessas. Lisboa: Instituto Piaget.

GARLAND, D. (2001). The Culture of Control. Oxford: Oxford University Press.

GARMENT, S. (1991). Scandal: The Culture of Mistrust in American Politics. New York: Times Books.

GEYH, C. G. (2006). Preserving Public Confidence in the Courts in an Age of Individual Rights and Public Skepticism. http://ssrn.com/abstract=933699: Indiana University School of Law-Bloomington.

GIBBONS, J. (ed.) (1994). Language and the Law. London: Longman.

GIBBONS, J. (2003). Forensic Linguistics. An Introduction to Language in the Justice System. Oxford: Blackwell.

GIBBONS, J. e TURELL, M. T. (eds.) (2008). Dimensions of Forensic Linguistics. Amsterdam: John Benjamins Publishing Company.

GOLDMAN, L. (1994). Accident and absolute liability in anthropology. In: Gibbons (ed.). Language and the Law. London: Longman.

GOODRICH, P. (1987). Legal discourse. Studies in Linguistics, Rhetoric and Legal Analysis. London: Macmillan.

GRABER, D. A. (1980). Crime News and the Public. New York: Praeger.

GREER, C. e JEWKES, Y. (2005). "Extremes of Otherness: Media Images of Social Exclusion». In: Social Justice, 32 (1), pp. 20-31.

GREIMAS, A. J. (1976). Analyse sémiotique d'un discours juridique. In Greimas, A. J.. Sémiotique et sciences sociales. Paris: Seuil.

GRICE, P. (1975). Logic and Conversation. In: Cole, P.; Morgan, J. L. (eds.). Syntax and Semantics 3: Speech Acts. New York: Academic Press.

GUTMANN, A. e THOMPSON, D. (2007), "O que significa democracia deliberativa", In: Revista Brasileira de Estudos Constitucionais, Belo Horizonte, Ed. Fórum, 2007, pp. 17-78.

HABERMAS, J. (1996). Between Facts and Norms. Contributions to a Discourse Theory of Law and Democracy, Cambridge, MA: MIT Press.

HABERMAS, J. (1996), "Three Normative Models of Democracy» In: Benhabib, S. (ed.) Democracy and Difference. Princeton, NJ: Princeton University Press.

HABERMAS, J. (1997). Direito e Democracia - Entre facticidade e validade, vol. II. Rio de Janeiro.

HABERMAS, J. (1998). The Structural Transformation of the Public Sphere: An Inquiry into a Category of Bourgeois Society, 9. ${ }^{\mathrm{a}}$ reimp., trad. de T. Burger. Cambridge, MA: MIT Press.

HABERMAS, J. (2002). "Prefacio a la Nueva Edición Alemana de 1990". In: Historia y Crítica de la Opinión Pública: La Transformación Estructural de la Vida Pública, trad. de F. Gil Martín, $7^{\text {a }}$. reimp., Barcelona: Gustavo Gilli.

HALl, S., CRITCHER, C., JEFFERSON, T., CLARKE, J. e ROBERTS, B. (1978). Policing the Crisis: Mugging, the State, and Law and Order, London: The MacMillan Press.

HARRIS, S. (1994). Ideological exchanges in British magistrates courts. In: Gibbons, J. (ed.). Language and the Law. London: Longman.

HJARVARD, S. (2008). "The Mediatization of Society: a Theory of the Media as Agents of Social and Cultural Change». In: Nordicom Review 29, 2, pp. 105-134. 
HOEY, M (1985). "The Statute as Discourse and the Lawyer as Linguist». In: Hall, R. A. J. (ed.) The Eleventh LACUS Forum 1984. Columbia: Hornbeam Press.

HONNETH, A. (1995). The Fragmented World of the Social: Essays in Social and Political Philosophy. New York: SUNY Press.

HUTCHINGS, P. (1999). «Spectacularizing crime: ghostwriting the law». In: Law and Critique, 10: pp. 27-48.

JACKSON, B. S. (1995). Making Sense in Law. Linguistic, Psychological and Semiotic Perspectives. Liverpool: Deborah Charles Publications.

JALALI, C. (2005). "Nova governação nova cidadania? Os cidadãos e a política em Portugal». In: Revista de Estudos Politécnicos, vol. II, n. ${ }^{\circ} 4$.

JIMÉNEZ, F. J. (1994). «Posibilidades y limites del escandalo politico como una forma de control social». In: REIS Revista Española de Investigaciones Sociológicas, pp. 7-36.

KELSEN, H. (1934). "The pure theory of law, its methods and fundamental concepts". In: Law Quarterly Review, n. ${ }^{\circ} 50$.

KISSELER, L., e HEIDEMANN, F. (2006). «Governança pública: novo modelo regulatório para as relações entre Estado, mercado e sociedade?». In: Revista da Administração Pública, 40 (3), Rio de Janeiro, Maio/Junho.

LAMBERT, P. (2004). "Le devoir de réserve et les notions voisines». In: AA VV. Actes de la Table Ronde organisée par l' Institut d'Études sur la Justice, le 17 octobre 2003, Bruxelles: Bruylant, pp. 9-19.

LEVI, J. N. e WALKer, A. G. (eds.) (1990). Language in the Judicial Process. New York: Plenum Press.

MACHADO, H. e SANTOS, F. (2009). A moral da justiça e a moral dos media: Julgamentos mediáticos e dramas públicos (Oficina do CES $n .^{\circ} 333$ ). Coimbra: CES.

MACHADO, H. e SANTOS, F. (2008). Crime, drama e entretenimento. O caso Maddie e a meta-justiça popular na imprensa portuguesa (Oficina do CES n. ${ }^{\circ}$ 308). Coimbra: CES.

Machado, J. (2002). Liberdade de Expressão. Dimensões constitucionais da esfera pública no sistema social. Coimbra: Coimbra Editora.

MACHADO, J. B. (2002). Introdução ao Direito e ao Discurso Legitimador. (13 $3^{\mathrm{a}}$ reimp.) Coimbra: Almedina.

MALEY, Y. (1994). The Language of the Law. In: Gibbons, J. (ed.). Language and the Law. London: Longman.

MANIN, B. (1987). "On Legitimacy and Political Deliberation». In: Political Theory, 15, pp 338-368.

MANSBRIDGE, J. (1999). "Everyday talk in deliberative system» In: Macedo, S. (ed.). Deliberative Politics: Essays on Democracy and Disagreement. New York: Oxford University Press.

MARMOR, A. (2008). "What Does the Law Say?»In: Analisi e diritto 2007. Ricerche di giurisprudenza analitica. Torino: G. Giappichelli Editore.

MASCARENHAS, Ó. (1998) "Por uma carta 98 da auto-regulação». In: AAVV. $3 .^{\circ}$ Congresso dos Jornalistas Portugueses - Conclusões, teses, documentos, Lisboa, Comissão Executiva do III Congresso dos Jornalistas Portugueses.

MASON, P. (2006) «Lies, distortion and what doesn't work: monitoring prison stories in the British media». In: Crime Media Culture, 2 (3), pp. 251-267.

MATHIESEN, T. (1995). "The eagle and the sun: on panoptical systems and mass media in modern society». In: Ericson, R. (ed.) Crime and the Media. Aldershot, Brookfield USA, Singapore, Sydney: Dartmouth, pp. 333-350. 
MATHIESEN, T. (2004). Essays on the creation of Acquiescense in Modern Society, Winchester: Waterside Press.

MATHIESEN, T. (2006). Prison on Trial, $3^{\mathrm{a}}$. ed., Winchester: Waterside Press.

MATOS, F. A. (2011). Responsabilidade Civil por Ofensa ao Crédito ou ao Bom Nome. Coimbra: Almedina.

MESQUITA, J. (1998). "Aprofundar a autonomia", In: AAVV. 3. ${ }^{\circ}$ Congresso dos Jornalistas Portugueses - Conclusões, teses, documentos. Lisboa: Comissão do III Congresso dos Jornalistas Portugueses.

MOREIRA, V. (1997). Auto-Regulação Profissional e Administração Pública. Coimbra: Almedina, 1997.

NEWBURN, T. e JONES, T. (2007). "Symbolizing crime control». In: Theoretical Criminology, 11(2), pp. 21-243.

OLSSON, J.(2004). Forensic Linguistics. An Introduction to Language, Crime and the Law. London: Continuum.

PAIXÃO, B. (2010). O escândalo político em Portugal (1991-1993 e 2002-2004). Coimbra: Minerva.

PATON, W. R. (1922). Polybius: The Histories, Volume III, Books 5-8 (Loeb Classical Library). London: Heinemann.

PRATT, J. (2007). Penal Populism, London, New York: Routledge.

PUTMAN, E. (1997). "Éthique des affaires et déontologie des professions d'affaires: réflexions sur la morale des marchands». In: BERGEL, J-L. (org.). Droit et Déontologies Professionnelles. Aix-en-Provence: Librairie de l'Université.

RAWLS, J. (1971). A Theory of Justice. Harvard: Harvard University Press.

RAWLS, J. (2001). O Direito dos Povos. São Paulo: Martins Fontes.

RIVERA BEIRAS, I. (2003). "State form, labor market and penal system: the new punitive rationality in context». In: Punishment Society, 7(2), pp. 167-182.

SANDERS, L. (1997). "Against deliberation». In: Political Theory, 25, pp. 347-376.

SANTOS, B. S. et al. (2009). A Justiça Penal: Uma Reforma em Avaliação. Coimbra: Centro de Estudos Sociais da Faculdade de Economia da Universidade de Coimbra.

SCHLESINGER, P. e TUMBER, H. (1994). Reporting Crime: The Media Politics of Criminal Justice. Oxford: Clarendon Press.

SCHLESINGER, P., TUMBER, H. e Murdock, G. (1995). "The media politics of crime and criminal justice». In: ERICSON, R. (coord.) Crime and the Media. Aldershot, Brokfield USA, Singapore, Sydney: Dartmouth, pp 397-420.

SCHUDSON, M. (1978). Discovering the news: a social history of American newspapers. New York: Basic Books.

SCHULZ, W. (2004). "Reconstructing Mediatization as an Analytical Concept». In: European Jounal of Communication Vol 19 (1), pp. 87-101.

SCHUMPETER, J. A. (1994). Capitalism, Socialism, and Democracy. London: Routledge.

SERRANO, E. (2007). "Pensar a regulação dos media numa sociedade em mudança». In: Comunicação e Sociedade ("Regulação dos media em Portugal»), vol. 11, Braga.

SHAPIRO, I. (1999). "Enough of deliberation: politics is about interest and power". In: Macedo, S. (ed.), Deliberative Politics: Essays on Democracy and Disagreement. New York: Oxford University Press.

SHETREET, S. e DESCHÊNES, J. (eds) (1985). Judicial Independence; the contemporary debate. Amsterdam: Martinus Nijhoff. 
SILVA, A. S., (2007). "A hetero-regulação dos meios de comunicação social». In: Comunicação e Sociedade, vol. 11, Braga.

SILVA, V. J. (2006). "Ordem e desordem jornalística». In: Diário de Notícias, 29 de Março.

SILVEIRINHA, M. J. (2004). Identidades, Media e Política: O Espaço Comunicacional nas Democracias Liberais, Lisboa: Livros Horizonte.

SILVEIRINHA, M. J. (2005). "Democracia deliberativa e reconhecimento: repensar o espaço político». In: Correia, J. C. Comunicação e Política. Covilhã: UBI.

SOURIOUX, J-L e LERAT, P. (1975). Le langage du droit. Paris: PUF.

STOFFEL-MUNCK, P., (1997). "Déontologie et moral». In: Bergel, J-L. (org.), Droit et Déontologies Professionnelles. Aix-en-Provence: Librairie de l'Université.

STYGALL, G. (2010). "Legal writing: complexity. Complex documents/average and not-so-average readers". In: Coulthard, M.; Johnson, A. (eds.) (2010). The Routledge Handbook of Forensic Linguistics. London: Routledge.

SURETTE, R. (2010). Media, crime, and criminal justice: images, realities and policies. $4 .{ }^{a}$ ed. Belmont: Wadsworth.

THOMAS, J. (1997). Judicial Ethics in Australia. Sydney: Law Book Co.

THOMPSON, J. (2005). "The new visibility". In: Theory, Culture E Society, 22(6),pp. 31-51.

THOMPSON, J. B. (2002). O escândalo político: poder e visibilidade na era da mídia. Petrópolis: Editora Vozes.

THORNTON, G. C. (1996). Legislative Drafting. London: Butterworth.

THUSSU, D. K. (2007). News as entertainment: the rise of global infotainment. London: Sage.

TIERSMA, P. M. (1993). «Linguistic Issues in the law». In: Language, 69, pp. 113-137.

TIERSMA, P. M. (2000). Legal Language. Chicago: The University of Chicago Press.

VALIER, C. (2002). Theories of Crime and Punishment. Harlow, New York: Longman.

VAN DIJK, T. A. (1990). La Noticia como Discurso: Comprensión, Estructura y Producción de la Información, Paidós: Barcelona.

VAN DIJK, T. A. (2005). Discurso, Notícia e Ideologia: Estudos na Análise Crítica do Discurso, trad. de Z. P. Coelho, Porto: Campo das Letras.

VAN OMMESLACHE, P. (1995) “L'autorégulation». In: AAVV, L'Autorégulation. Bruxelas: Bruylant.

VERDUSSEN, M. (2004). "Le devoir de réserve au regard de la jurisprudence de la Cour Européenne des Droits de l'Homme». In: AA VV, Actes de la Table Ronde organisée par l' Institut d' Études sur la Justice, le 17 Octobre 2003. Bruxelles: Bruylant, pp. 21-31.

VILlEY, M. (1974). "Préface». In: Archives de Philosophie du Droit, Tome XIX.

VILLEY, M., KALINOWSKI, G. e GARDIES, J-L. (1974). "Indicatif et impératif juridiques. Dialogue à trois voix". In: Archives de Philosophie du Droit, Tome XIX.

VIRALlY, M. (1966). "Le phénomène juridique». In: Revue de Droit Public.

WACQUANT L. (2001). "How penal common sense comes to Europeans: notes on the transatlantic diffusion of neoliberal doxa». In: European Societies, 1 (3), pp. 319-352.

WEICHER, M. E. e GOLDSCHMIDT, J. (2007). "The Expansion of the First Amendment in Judicial Elections: Another Cause for Reform». In: Loyola University Chicago Law Journal, pp. 833-894.

WEICK, K. E. (1995). Sensemaking in Organizations. London: Sage. 
WIENER, J. (1988). Papers for the millions; the new journalism in Britain, 1850-1914. New York: Greenwood.

WIIO, O. A. (1995). "Organizational communication. Contingent views». In: Goldhaber G.M.; Barnett G. A. (eds.). Handbook of Organizational Communication. Norwood: Ablex.

WILliAMS, G. (1945). Language and the Law (artigo em 5 partes). In: The Law Quarterly Review 61 (4 partes) e 62 (5. ${ }^{\mathrm{a}}$ parte).

WOLTON, D. (1995). "As contradições do espaço público mediatizado". In: Revista de Comunicação e Linguagens, 21-22, pp. 167-188.

YOUNG, I. M. (2000). Inclusion and Democracy. Oxford: Oxford University Press. 